\title{
The Bentall procedure: Is it the gold standard? A series of 597 consecutive cases
}

\author{
Christian D. Etz, MD, PhD, Moritz S. Bischoff, MD, Carol Bodian, DrPH, Fabian Roder, MS, \\ Robert Brenner, BS, Randall B. Griepp, MD, and Gabriele Di Luozzo, MD
}

Objectives: We compared aortic root reconstructions using conduits with biological valves and mechanical valves.

\begin{abstract}
Methods: Of 597 patients (1995-2008), 307 (mean age 71 years [23-89 years]) had biological valves and 290 (mean age 51 years [21-82 years]) had mechanical valves. The subgroup of 242 patients aged 50 to 70 years included 133 with biological and 109 with mechanical valves.

Results: Overall hospital mortality was $3.9 \%$ with biological valves $(n=15$; elective: $3.7 \%[n=10])$ versus $2.8 \%$ with mechanical valves $(\mathrm{n}=8$; elective: $1.4 \%[\mathrm{n}=3])$. In patients 50 to 70 years, age greater than 65 years (relative risk: $3.3[P=.0001]$ ), clot (relative risk: $2.5[P=.05]$ ), coronary artery disease (relative risk:3.5 $[P<.0001]$ ), and degenerative etiology (relative risk: $0.4[P=.006])$ were independent risk factors for longterm survival (after postoperative day 30); there was no difference in long-term survival between biological and mechanical valves (relative risk: $0.9[P=.74]$ ). The linearized rate for valve/ascending aorta reoperation was $0.86 \% / \mathrm{pt}-\mathrm{y}$ ( 2 in 2310 pt-y) after mechanical valves and $2.5 \% / \mathrm{pt}-\mathrm{y}$ (4 in $1586 \mathrm{pt}-\mathrm{y})$ after Bentall procedures with the biological valve.
\end{abstract}

Conclusions: The choice of valve for aortic root reconstruction seems to have no influence on long-term outcome. Emergency operation and the presence of clot/atheroma have a significant impact on short-term outcome. Reoperation for either ascending aorta and/or aortic valve is low. (J Thorac Cardiovasc Surg 2010;140:S64-70)

Aortic root replacement with reattachment of the 2 main coronary arteries was originally described by Bentall and De Bono. ${ }^{1}$ The operation has undergone many alterations during the past 3 decades. $^{2}$ Notable adaptations have been the creation of an aortic cuff around the coronary ostia and extensive mobilization and attachment of the coronary buttons. Although the operation was originally designed to treat patients with aortic root aneurysms, the indications for radical root replacement have expanded..$^{3-5}$

The Bentall procedure has led the way for the development of other techniques for root replacement, such as aortic valve-sparing procedures. The potential advantage of these procedures is freedom from the need for anticoagulation and consequent low morbidity. ${ }^{6}$ Although the Bentall procedure is a durable operation, with a low ascending aorta and valve reoperation rate, the replacement of the aortic valve with a mechanical prosthesis carries a significant

\footnotetext{
From the Departments of Cardiothoracic Surgery and Anesthesia, Mount Sinai School of Medicine, New York, NY.

Disclosures: Christian D. Etz, Moritz S. Bischoff, Carol Bodian, Fabian Roder, Robert Brenner, Randall B. Griepp, and Gabriele Di Luozzo have nothing to disclose with regard to commercial support.

Received for publication April 28, 2010; accepted for publication July 12, 2010

Address for reprints: Gabriele Di Luozzo, MD, Assistant Professor, Mount Sinai School of Medicine, Department of Cardiothoracic Surgery, 1190 Fifth Ave, Box 1028, New York, NY 10029 (E-mail: gabriele.diluozzo@mountsinai.org). $0022-5223 / \$ 36.00$

Copyright (c) 2010 by The American Association for Thoracic Surgery doi:10.1016/j.jtcvs.2010.07.033
}

lifetime risk of both thromboembolism and major hemorrhagic complications. $^{3}$

The choice of which operation to perform for aortic root disease is multifaceted and influenced by the preferences of both patient and surgeon. The young patient $(<40$ years old) who wishes to avoid anticoagulation, or in whom it is contraindicated, will likely benefit from an aortic valvesparing procedure ${ }^{6}$ if he or she has a competent aortic valve and minimal valve deformity. Patients over the age of 70 years are likely to benefit most from aortic root replacement with a biological valve (BV), which has a low probability of rapid structural deterioration in older patients and a low rate of stroke and reoperation. ${ }^{7}$ However, patients between 50 and 70 years old are often offered a choice between a mechanical valve (MV) and a stented bioprosthesis (BV) for the Bentall procedure.

We report our experience with 597 consecutive patients who have undergone a Bentall procedure with an MV or stented BV during a 13-year period. We highlight the long-term outcomes of patients as a function of valve choice. In the 50- to 70-year age group, in which either valve type has been considered reasonable for some years, we compare the outcomes of the Bentall procedure with MV and BV.

\section{METHODS}

Our analysis includes patients operated on from 1995 to 2008; before 1995 , only a limited number of Bentall operations with the BV were performed $(\mathrm{BV}=3, \mathrm{MV}=133)$. The study was approved by the institutional review board without a requirement for individual patient consent. 


\section{Abbreviations and Acronyms \\ $\mathrm{BV}=$ biological valve \\ $\mathrm{CABG}=$ coronary artery bypass grafting \\ $\mathrm{MV}=$ mechanical valve \\ SMR $=$ standardized mortality ratio}

A total of 597 were analyzed retrospectively: $103(17.2 \%)$ had urgent or emergency procedures and $49(8.2 \%)$ were admitted with acute type A dissection. Further patient characteristics are listed in Table 1.

In most patients, the indication for a Bentall procedure was the presence of aortic valve dysfunction severe enough to warrant aortic valve replacement; for these patients, the aortic root was replaced if the ascending aorta exceeded 4 to $4.5 \mathrm{~cm}$ in diameter and the patient's life expectancy was anticipated to be greater than 10 years. In patients with bicuspid aortic valve but without severe valvular dysfunction, the Bentall procedure was done if the ascending aortic diameter was greater than $5.5 \mathrm{~cm}$ or if they had type A dissection.

\section{Surgical Technique}

All patients included in this study had a button Bentall operation, a modification of the original technique described by Kouchoukos and coworkers ${ }^{2}$ in 1991. All operations were performed with an open distal anastomosis using a period of deep hypothermic circulatory arrest, often with hemiarch replacement, but occasionally involving replacement of the entire arch. Our current technique and its rationale have been previously described in detail. ${ }^{8}$

In brief, cannulation for cardiopulmonary bypass was through the femoral artery in the majority of patients through 1999. In 2000, cannulation of the right axillary artery became the standard approach. The temperature was lowered to $20^{\circ} \mathrm{C}$ during the proximal aortic reconstruction and then to $12^{\circ} \mathrm{C}$ to $15^{\circ} \mathrm{C}$ before circulatory arrest. A jugular venous catheter was placed to measure mixed venous saturation during cooling.

After sizing of the aortic annulus, a series of pledget-supported mattress sutures was placed from the ventricular to the aortic aspect of the annulus for fixation of a heterograft. Annular stitches engaged both the valve sewing ring and the vascular graft to facilitate subsequent replacement of the heterograft valve within the conduit. For a prosthetic MV, the sutures were placed from the aortic to the ventricular aspect of the annulus to effect intra-annular fixation of the valve. A composite of a St Jude Medical valve (St Jude Medical, Inc, St Paul, Minn) and a Hemashield graft (Boston Scientific Corp, Wayne, NJ) was used in MV cases. The BV option involved a homemade composite of a pericardial valve (Edwards Lifesciences LLC, Irvine, Calif) or porcine valve (Medtronic, Inc, Minneapolis, Minn) and a Hemashield graft. After the proximal suture line was completed, the diseased aortic segment was resected, and buttons including the coronary ostia were excised. The first centimeter of the coronary arteries was mobilized, and the buttons were implanted in an end-to-side fashion with a running suture incorporating a polytetrafluoroethylene (Teflon) felt strip to reinforce the adventitial surface of the coronary arteries.

\section{Choice of Valve: BV Versus MV}

Patients older than 65 years of age and those with contraindications to anticoagulation were generally advised to opt for a BV. Patients younger than 55 years of age usually received an MV unless a contraindication to anticoagulation was present, but some active younger patients preferred a BV despite understanding that this would lead eventually to a second operation.

Patients with a BV were advised to take $325 \mathrm{mg}$ of aspirin daily for the first 3 months. Although no sodium warfarin (Coumadin) was mandated by the surgeons, some patients were placed on a long-term regimen of anticoagulants for other indications by their referring physicians during follow-up. All patients with MVs were treated with warfarin, with a target international normalized ratio of 2.0 to 2.5 .

\section{Follow-up}

A retrospective review of these patients was conducted using data gathered contemporaneously and supplemented from patient medical records. Follow-up information was gathered from yearly routine computed tomographic scans (with contrast) of the aorta, direct telephone interview of the patient or a close relative, and contact with the referring physician.

\section{Statistical Methods}

Data were entered in an Excel (Microsoft Corp, Redmond, Wash) spreadsheet and transferred to a SAS (SAS Institute, Inc, Cary, NC) file for data description and analysis. Characteristics are described as percentages, medians, or as means and standard deviations. Kaplan-Meier life tables were calculated for the risk of death.

Follow-up was measured from the date of the operation to the earlier of either the date of death or the last contact alive. Short-term mortality or hospital mortality was defined as death during the initial hospitalization regardless of number of days, or death within 30 days of the procedure among patients discharged alive. Risk factors for short-term mortality were analyzed by $\chi^{2}$ tests and multiple logistic regression.

Long-term follow-up was calculated for survivors of hospital mortality, commencing 30 days after the procedure and terminating at the earlier of either death or last contact alive for survival estimates. For long-term adverse events, follow-up time was terminated at the time of their occurrence. Long-term adverse events included death and morbid conditions as defined by Edmunds and coworkers ${ }^{9}$ : stroke, hemorrhage necessitating transfusion or hospitalization, peripheral embolization, and endocarditis. The Cox proportional hazards model and Kaplan-Meier survival curves, and their comparisons with New York State mortality, were used to analyze and describe long-term survival. Annualized person-year event rates were estimated for long-term survival and for adverse events. Poisson regression provided significance tests of standardized mortality ratios (SMRs) of observed deaths relative to the number of deaths expected on the basis of New York State mortality rates for comparable ages, calendar time, follow-up years, and for tests comparing SMRs.

Because of the demographic differences between the groups as a whole, detailed comparisons of outcomes between patients undergoing Bentall procedures with MV and BV were limited to the age group between 50 and 70 years. For similar reasons, long-term outcomes were assessed using comparisons between age- and sex-matched normal New York State control populations for each valve type. Analysis of risk factors for early and long-term mortality could not be carried out in some subgroups in which there were very few deaths.

\section{RESULTS}

\section{Preoperative Patient Characteristics}

The demographic data, preoperative risk factors, and operative details of the 597 patients analyzed are summarized in Table 1. There were 458 men and 139 women, with a median age of 63 years (21-89 years); there were $307 \mathrm{BV}$ and $290 \mathrm{MV}$ operations. Hypertension was present in $52 \%$ of the patients; coronary artery disease was evident in $26 \% ; 25 \%$ had a history of smoking; and $110(18.4 \%)$ patients had acute dissection. The mean diameter of the ascending aorta was $6.0 \pm 1.2 \mathrm{~cm}$.

\section{Intraoperative Characteristics}

Approximately $32 \%$ of the patients underwent a concomitant procedure; $26 \%$ (155 patients) had coronary artery 
TABLE 1. Demographics, preoperative clinical and operative characteristics

\begin{tabular}{|c|c|c|c|}
\hline Variable & All patients $(n=597)$ & Mechanical valve $(n=290)$ & Biological valve $(n=307)$ \\
\hline Age (median) in years & $63(21-89)$ & $51(21-82)$ & $71(23-89)$ \\
\hline Male & 458 (76.7) & $233(80.3)$ & $225(73.3)$ \\
\hline \multicolumn{4}{|l|}{ Risk factors } \\
\hline Hypertension & $313(52.4)$ & $132(45)$ & $181(59)$ \\
\hline Atheroma & $26(4.4)$ & $4(1.4)$ & $22(7.2)$ \\
\hline Clot & $26(4.4)$ & $6(2.1)$ & $20(6.5)$ \\
\hline Smoking & $155(25.9)$ & $73(25.2)$ & $82(27)$ \\
\hline IDDM & $39(6.5)$ & $20(6.9)$ & $19(6.2)$ \\
\hline COPD & $20(3.4)$ & $8(2.8)$ & $12(3.9)$ \\
\hline CAD (coronary artery disease) & $151(25.3)$ & $46(15.9)$ & $105(34.2)$ \\
\hline Neurologic & $39(6.5)$ & $14(4.8)$ & $25(8.1)$ \\
\hline Renal failure (dialysis) & $8(1.3)$ & $1(.34)$ & $7(2.3)$ \\
\hline \multicolumn{4}{|l|}{ Etiology } \\
\hline Atherosclerosis & $64(10.7)$ & $14(4.8)$ & $50(16.3)$ \\
\hline Degenerative & $332(55.6)$ & 149 (51.4) & $183(59.6)$ \\
\hline Dissection & $110(18.4)$ & $62(21.4)$ & $48(15.6)$ \\
\hline Other & $91(15.2)$ & $65(22.4)$ & $26(8.5)$ \\
\hline Bicuspid aortic valve & $168(28.1)$ & $98(34)$ & $82(27)$ \\
\hline Marfan & $14(2.3)$ & $13(4.5)$ & $1(0.32)$ \\
\hline \multicolumn{4}{|l|}{ Timing of operation } \\
\hline Emergency & $58(9.7)$ & $43(14.8)$ & $15(4.9)$ \\
\hline Urgent & $45(7.5)$ & $25(8.6)$ & $20(6.5)$ \\
\hline $\begin{array}{l}\text { Significant aortic valve } \\
\text { insufficiency (AR) }\end{array}$ & $340(57)$ & $174(60)$ & $166(54.1)$ \\
\hline \multicolumn{4}{|l|}{ Operative data } \\
\hline Ascending aortic diameter (mean) & $60 \pm 1.2$ & $5.7 \pm 1.2$ & $6.0 \pm 1.2$ \\
\hline Previous cardiac surgery & $109(18.3)$ & 57 & 52 \\
\hline \multicolumn{4}{|l|}{ Extent of aortic resection } \\
\hline Hemiarch & $228(38.2)$ & $113(39.0)$ & $115(57.5)$ \\
\hline Arch, other & $34(15.7)$ & $13(4.5)$ & $21(6.8)$ \\
\hline Ascending only & $335(56.1)$ & $164(56.6)$ & $171(55.7)$ \\
\hline \multicolumn{4}{|l|}{ Concomitant surgery } \\
\hline $\mathrm{CABG} \pm$ other & $155(26.0)$ & $46(15.9)$ & $109(35.5)$ \\
\hline Not CABG & $32(5.4)$ & $15(5.2)$ & $17(5.5)$ \\
\hline Neither & $410(68.7)$ & $229(79.0)$ & $181(59.0)$ \\
\hline CPB time (min) & $252 \pm 60$ & $244 \pm 61$ & $260 \pm 58$ \\
\hline HCA time (min) & $24.2 \pm 13.6$ & $24.4 \pm 12.8$ & $23.9 \pm 14.3$ \\
\hline Aortic crossclamp time (min) & $176 \pm 49$ & $168 \pm 48$ & $183 \pm 49$ \\
\hline Minimal esophageal temp $\left({ }^{\circ} \mathrm{C}\right)$ & $13.3 \pm 5.3$ & $13.2 \pm 5.2$ & $13.3 \pm 5.3$ \\
\hline
\end{tabular}

$A R$, Aortic regurgitation; $C A B G$, coronary artery bypass grafting; $C A D$, coronary artery disease; $C O P D$, chronic obstructive pulmonary disease; $C P B$, cardiopulmonary bypass; $H C A$, hypothermic circulatory arrest; $I D D M$, insulin-dependent diabetes mellitus; $C A B G$, coronary artery bypass graft procedure; other, additional valve or aortic operation; $\min$, minutes.

bypass grafting $(\mathrm{CABG})$ with or without another procedure and $5.4 \%$ underwent another concomitant procedure. The Bentall procedure was a reoperation in $109(18.3 \%)$ patients. The mean aortic crossclamp time was $176.8 \pm$ 49 minutes, and total hypothermic circulatory arrest time was $24.2 \pm 13.6$ minutes. Further operative characteristics are outlined in Table 1.

\section{Short-Term Outcomes}

Overall 30-day mortality was 3.9\%: $2.8 \%$ for MV patients and $4.9 \%$ for BV patients. Mortality for emergency operations was $9.7 \%(10 / 103)$. Sixteen $(2.7 \%)$ patients had a permanent stroke, including $7 \mathrm{MV}(2.4 \%)$ and $9 \mathrm{BV}$ patients $(2.9 \%)$. Temporary neurologic dysfunction occurred in $14.4 \%$, renal failure in $2.2 \%$, and pulmonary failure in $13 \%$. The mean intensive care unit stay was 3.8 days, and the mean hospital stay was 12.8 days. Further short-term adverse outcomes are outlined in Table 2.

\section{Risk Factors for Hospital Mortality}

Various risk factors were analyzed for their impact on hospital mortality (Table 3 ). In all patients older than 20 years, the risk factors associated with mortality were clot $(P=.005)$, emergency operation $(P<.001)$, concomitant 
TABLE 2. In-hospital post-operative complications

\begin{tabular}{lccc}
\hline Complications & Total & Mechanical & Biological \\
\hline Death & $23(3.9)$ & $8(2.8)$ & $15(4.9)$ \\
Bleeding & $20(3.4)$ & $9(3.1)$ & $11(3.5)$ \\
Cardiac & $65(11)$ & $36(12.4)$ & $29(9.4)$ \\
Neurologic & & & \\
$\quad$ Temp & $86(14.4)$ & $35(12)$ & $51(16.6)$ \\
$\quad$ Perm & $16(2.7)$ & $7(2.4)$ & $9(2.9)$ \\
Pulmonary & $78(13)$ & $41(14.1)$ & $37(12)$ \\
Renal & $13(2.2)$ & $7(2.4)$ & $6(2.0)$ \\
Infection & $29(4.9)$ & $18(6.2)$ & $11(3.6)$ \\
\hline
\end{tabular}

Temp, Temporary neurologic dysfunction; Perm, permanent neurologic injury.

CABG $(P=.007)$, reoperation $(P=.004)$, and smoking $(P=.02)$. The type of valve implanted-BV or MV—did not influence hospital mortality $(P=0.19)$. In the 50 - to 70-year age group, emergency $(P=.005)$ and clot $(P=.001)$ were risk factors associated with in-hospital mortality.

Of a number of possible preoperative risk factors for inhospital mortality analyzed, clot, reoperation, smoking, emergency operation, and CABG emerged as significant. None of the 236 patients without any of these risk factors died. With 1 risk factor, in-hospital mortality was 3.3\% (8/242), with 2 risk factors it was $9.4 \%$ (9/96), and with 3 preoperative risk factors, $26.1 \%(6 / 23)$.

\section{Long-Term Outcomes}

During follow-up beyond 10 years (median, 6.6 years; range, 0-14.6 years), there were $104 \mathrm{BV}$ and $49 \mathrm{MV}$ late deaths. A total of 421 patients were alive according to the Social Security Death Index database, and $383(91 \%)$ of the patients or next of kin were contacted by telephone: $212(55.3 \%)$ with MV and $171(44.6 \%)$ with BV. Longterm follow-up for the 50- to 70-year age was complete in

TABLE 3. Predictors of hospital mortality

\begin{tabular}{|c|c|c|c|c|c|c|}
\hline & \multirow{2}{*}{\multicolumn{3}{|c|}{$\begin{array}{c}\text { Hospital mortality } \\
(\text { aged } \geq 20 \text { y })\end{array}$}} & \multirow{2}{*}{\multicolumn{3}{|c|}{$\begin{array}{c}\begin{array}{c}\text { Hospital mortality } \\
(\text { aged 50-70 y })\end{array} \\
\text { MV and BV }(\mathbf{n}=10)\end{array}$}} \\
\hline & & & & & & \\
\hline & OR & $(95 \%$ CI $)$ & $P$ value & OR & $(95 \%$ CI $)$ & $P$ value \\
\hline \multicolumn{7}{|l|}{ Age $>65$ y } \\
\hline $\begin{array}{l}\text { Clot } \\
\text { CAD }\end{array}$ & 5.2 & $1.6-16.4$ & .005 & 11.1 & $2.5-40.9$ & .001 \\
\hline Emerg & 8.7 & $3.1-24.3$ & $<.0001$ & 10.1 & $2.1-58.3$ & .005 \\
\hline CABG & 3.7 & $1.4-9.3$ & .007 & & & \\
\hline Reop & 4.0 & $1.5-10.1$ & .004 & & & \\
\hline Smoker & 3.0 & $1.2-7.3$ & .02 & & & \\
\hline MV & 0.5 & $0.2-1.4$ & .19 & & & \\
\hline
\end{tabular}

TABLE 4. Predictors of Long-term mortality

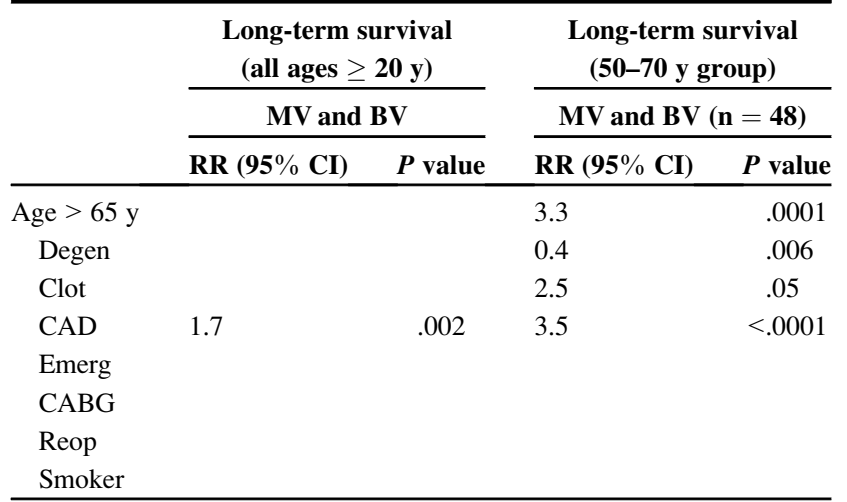

$M V$, Mechanical valve; $B V$, biological valve; $R R$, relative ratio; $C I$, confidence interval; Degen, degenerative; $C A D$, coronary artery disease; Emerg, emergency operation; $C A B G$, coronary artery bypass graft procedure; Reop, reoperation; smoker, history of smoking.

$175(92.6 \%)$ of 189 patients. Of the 383 patients contacted, 41 patients or next of kin reported a stroke, and 35 patients had a major bleeding event that required either transfusion or hospitalization.

The risk factors for long-term survival were calculated for both the older than 20 years and the 50- to 70-year-old age groups (Table 4 ). In the older than 20 years, the only risk factor associated with mortality was CAD $(P=.002)$. In the 50- to 70-year-old patients, age older than 65 years $(P=.0001)$, CAD $(P<.001)$, and clot $(0.05)$ were risk factors associated with long-term mortality. The presence of a degenerative aneurysm was protective against long-term mortality $(\mathrm{RR}=0.4, P=.006)$.

The SMR of our cohort in comparison with New York State age- and sex-matched population, starting 30 days postoperatively, was 1.5 for $\mathrm{BV}(P<.0001)$ and 1.7 for MV $(P<.0001)$. There was no significant difference in the relative risk between $\mathrm{BV}$ and $\mathrm{MV}$ patients $(P=.58)$ on the basis of valve type. The SMRs for women and men in both the BV and MV groups were significantly higher than those of the New York State age- and sex-matched populations described in Table 5. The long-term survival for BV and MV patients in the 50- to 70-year age group is shown in Figure 1.

The impact of the significant preoperative risk factors on long-term survival was calculated using New York State age- and sex-matched mortality rates. Again, the important preoperative risk factors were clot, $\mathrm{CABG}$, reoperation,

TABLE 5. Standardized mortality ratio of our cohort versus New York State age- and sex-matched population

\begin{tabular}{lll}
\hline & \multicolumn{1}{c}{ Mechanical } & \multicolumn{1}{c}{ Biological } \\
\hline Men & $66 / 51.8=1.3(P=.03)$ & $39 / 23=1.7(P=.0005)$ \\
Women & $38 / 16.4=2.3(P<.0001)$ & $10 / 5.8=1.7(P=.05)$ \\
Totals & $104 / 68.2=1.5(P<.0001)$ & $49 / 29=1.7(P<.0001)$ \\
\hline
\end{tabular}




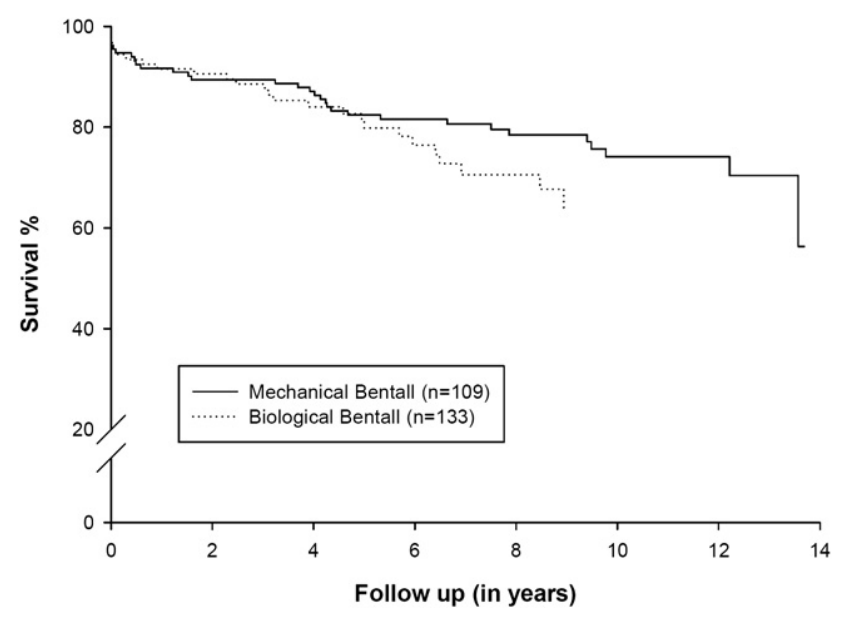

FIGURE 1. Kaplan-Meier curve of 242 patients, aged 50 to 70 years, after Bentall procedure with biological $(n=133)$ or mechanical $(n=109)$ valve (survival is calculated starting from the procedure).

emergency operation, and smoking. The SMRs for patients with up to 3 preoperative risk factors were analyzed (Table 6 ), and their long-term survival curves are shown in Figure 2.

\section{Adverse Outcomes and Event Rates}

Six patients required reoperation on either the ascending aorta or aortic valve during follow-up: 2 with MVs and 4 with BVs. The linearized rate for valve/ascending aortic replacement for both valve types was $1.54 \% / p t-y \quad(6 / 3896$ person-years): $0.86 \% / p t-y(2 / 2310$ pt-y) after MV and $2.5 \% / \mathrm{pt}-\mathrm{y}(4 / 1586 \mathrm{pt}-\mathrm{y})$ after the BV Bentall procedure. The adverse event rate for the 50- to 70-year age group was defined as the occurrence of stroke and/or death. The linearized rate of stroke (12/126) and/or death (20/126) for MV Bentall was 3.0\%/pt-y (32 in1054 pt-y). The linearized rate of stroke (10/102) and/or death (23/102) for BV Bentall was $5.6 \% / p t-y$ ( 33 in 585 pt-y).

\section{COMMENTS}

In accord with the reports of others, we experienced significant reduction in hospital mortality as our experience with aortic root replacement increased. Before 1990, the mortality for an MV Bentall procedure was $9.1 \%$; mortality decreased to $1.1 \%$ after 2005 . Similar favorable outcomes were seen in the BV Bentall cases: between 1993 and
1998 there was a mortality of $10.9 \%$, and after 2005 the mortality was reduced to $4.2 \%$. For the years covered in this study, the overall in-hospital mortality was $3.9 \%$.

There are several probable reasons for the higher mortality in BV than in MV patients: a higher median age (71 vs 51 years) and an increased burden of atherosclerosis, reflected by a greater number of CABG operations: $34 \%$ vs $15 \%$. In the $\mathrm{BV}$ group, patients requiring $\mathrm{CABG}$ had a 5-fold increase in mortality over those without CABG (Table 3). The BV group had more patients with a preoperative history of neurologic events, further underscoring the likelihood of underlying aortic atherosclerosis, cerebrovascular disease, and clot in this cohort. The difference in mortality is expected, given our practice of implanting BVs in older patients and those with multiple, life-limiting comorbidities.

Despite a myriad of etiologies for ascending aorta dilatation and valve dysfunction, the Bentall operation can be performed safely in an elective setting with a mortality of $2.6 \%$. Patients without any preoperative risk factors can proceed with surgery with favorable short- and long-term survival (Figure 2). In our prior report on the Bentall operation, the in-hospital mortality for the subgroup of patients less than 65 years of age without need for concomitant procedures was $0.7 \% .^{10}$ An emergency or urgent aortic root replacement carries a significantly higher operative mortality: 9.7\%: Emergency operation increases the risk of operation 5 -fold, and the presence of clot or atheroma carries an 8 -fold increase in hospital mortality. In a patient with 2 or 3 preoperative risk factors, the operative risk increases 6-fold to 26-fold, and long-term survival is less favorable. Bachet and associates ${ }^{11}$ have reported a $21 \%$ hospital mortality for aortic root replacements in acute aortic dissection, indicating the technical challenge of this operation in managing delicate, friable tissue, and the negative impact of malperfusion and thromboembolism. The emergency Bentall cohort represents a mixture of patients that include acute aortic dissections, ruptured aneurysms, and pseudoaneurysms, which are likely to be associated with a higher prevalence of clot or atheroma and the need for ad hoc coronary revascularization (Table 1).

The valve-related morbidity cannot be estimated accurately in this large population of patients because the cause of death was available in only 76 of 176 late deaths; $91 \%$ of the living patients $(383 / 421)$ or their relatives, however, were interviewed. A combined total of 41 strokes and 35

TABLE 6. Standardized mortality ratio of patients $>20$ years with identified preoperative risk factors compared to New York State age- and sex-matched population

\begin{tabular}{lcccccccc}
\hline No. of factors & $\mathbf{N}$ & Median year & Median age & No. of deaths & Expected deaths & SMR & 95\% CI & $\boldsymbol{P}$ value \\
\hline 0 & 236 & 2002 & 57 & 38 & 32.2 & 1.2 & $(.86,1.6)$ & .31 \\
1 & 234 & 2000 & 63 & 68 & 44.5 & 1.5 & $(1.2,1.9)$ & .0005 \\
2 & 87 & 1999 & 68 & 38 & 23.1 & 1.6 & $(1.2,2.3)$ & .002 \\
3 & 17 & 1999 & 67 & 9 & 3.2 & 2.8 & $(1.4,5.3)$ & .002 \\
\hline
\end{tabular}

SMR, Standardized mortality; $95 \% C I$, confidence interval; $N$, number of patients. 


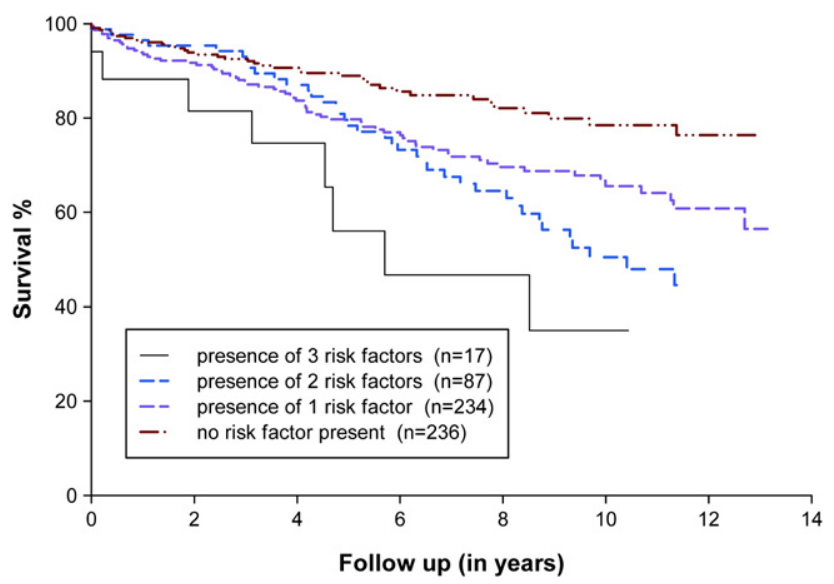

FIGURE 2. Kaplan-Meier curve of the long-term survival of patients after Bentall operation according to the number of identified preoperative risk factors (smoking, coronary artery bypass graft, reoperation, emergency, and clot).

major hemorrhagic events were tabulated from patients both dead and alive. Our previous publication with BV Bentall operations estimated the rate of stroke at $0.85 / 100 \mathrm{pt}-\mathrm{y}$ and significant hemorrhage as $0.3 / 100$ pt-y. ${ }^{7}$ In patients with bicuspid valves, the linearized stroke rate was $0.7 /$ $100 \mathrm{pt}-\mathrm{y}$ and that of hemorrhage, $0.5 / 100 \mathrm{pt}-\mathrm{y} .{ }^{3}$ In the 50 to 70-year age group, the linearized adverse event rate (stroke and/or death) was 3.0\%/pt-y (32/1054 pt-y) for MV and 5.6\%/pt-y (33/585 pt-y) for BV. The favorable long-term survival in the 50-to 70-year age group irrespective of valve type suggests good compliance with and management of anticoagulation and a low incidence of valve-related complications. The low absolute number of adverse events in the contacted patients may reflect contemporary strategies - principally lower international normalized ratio goals and self-management of anticoagulation therapy-in patients with MV. ${ }^{12}$ In addition to lower thromboembolic and bleeding events, Koertke and colleagues ${ }^{13}$ have shown improved survival in self-managed patients. Bryne and coworkers ${ }^{14}$ reported a similar 5-year freedom from valve-related complications with $\mathrm{BV}$ and $\mathrm{MV}$ aortic root replacements (BV 93\% vs MV 86\%).

$\mathrm{We}^{7}$ previously reported the unexpected finding of poorer long-term survival in female patients after aortic root reconstruction compared with an age-matched population. In the present analysis, female patients were twice as likely to die during follow-up as in a matched population. Moreover, in general, women have a poorer outcome after cardiovascular surgery than men. ${ }^{15,16}$ In several studies, preoperative risk profile, incidence of neurologic complications, and incomplete revascularization with $\mathrm{CABG}$ have all been significantly higher in women.

Observed deaths in both men and women were significantly higher than expected in a New York State age- and sex-matched population (Table 5). We previously showed that patients with bicuspid aortic valve had a normal life expectancy after a Bentall operation. ${ }^{3}$ In the current analysis, patients with bicuspid aortic valve composed only one third of the cohort, albeit $50.6 \%$ of the degenerative ascending aortic aneurysms, the major etiology leading to a Bentall operation ( $55 \%$ overall). Degenerative aneurysms had a favorable effect on long-term outcome in the 50- to 70-year age group (relative risk $=0.4, P=.006$ ). There are numerous other diseases treated with the Bentall procedure that may account for a diminished long-term survival. After proximal aortic surgery for aortic dissection, for example, patients have a late risk of death approximately twice that of a healthy population. $^{17}$

The current data may suggest a modification to current clinical practice with respect to valve selection. Patients under the age of 50 years may continue to select an aortic MV for a Bentall operation owing to the low long-term valverelated complication rate suggested by our data and underscored by other authors. ${ }^{12-14}$ Contemporary anticoagulation protocols, self-monitoring, and new, safer, predictable anticoagulants on the horizon make aortic MVs attractive to the young patient. However, proper patient selection in this age group may allow patients with aortic valve-sparing root replacement to fare as well or better in the long term with respect to need for reoperation and incidence of morbid complications. Patients in the 50- to 70-year age group may also reasonably be offered a BV Bentall procedure, inasmuch as valve-related complications and need for reoperation are relatively low. Furthermore, reoperation for prosthetic BV dysfunction requires only a valve replacement rather than rereplacement of the composite root, reducing perioperative mortality and morbidity. In addition, percutaneous or transapical aortic valve replacement may become routine methods for elderly patients requiring reoperation.

This study of 597 patients highlights the excellent shortand long-term outcomes with the Bentall procedure for a multitude of aortic diseases. The strength of the operation lies in its wide applicability and reproducibility. The choice of valve type does not affect early or late outcomes, as shown in the 50- to 70-year age group. However, the data clearly indicate that emergency operation and clot have a negative impact on in-hospital and long-term outcome. A carefully orchestrated aortic aneurysm surveillance program and timely elective surgery can circumvent the higher mortality and complication rates associated with emergency operations.

\section{References}

1. Bentall H, De Bono A. A technique for complete replacement of the ascending aorta. Thorax. 1968;23:338-9.

2. Kouchoukos NT, Wareing TH, Murphy SF, Perrillo JB. Sixteen-year experience with aortic root replacement. Results of 172 operations. Ann Surg. 1991;214: 308-18; discussion 318-20. 
3. Etz CD, Homann TM, Silovitz D, Spielvogel D, Bodian CA, Luehr M, et al. Longterm survival after the Bentall procedure in 206 patients with bicuspid aortic valve. Ann Thorac Surg. 2007;84:1186-93; discussion 1193-84.

4. Hagl C, Galla JD, Lansman SL, Fink D, Bodian CA, Spielvogel D, et al. Replacing the ascending aorta and aortic valve for acute prosthetic valve endocarditis: is using prosthetic material contraindicated? Ann Thorac Surg. 2002;74(5): S1781-5; discussion S1792-9.

5. Halstead JC, Spielvogel D, Meier DM, Rinke S, Bodian C, Malekan R, et al. Composite aortic root replacement in acute type A dissection: time to rethink the indications? Eur J Cardiothorac Surg. 2005;27:626-32; discussion 632-3.

6. David TE, Armstrong S, Maganti M, Colman J, Bradley TJ. Long-term results of aortic valve-sparing operations in patients with Marfan syndrome. J Thorac Cardiovasc Surg. 2009;138:859-64; discussion 863-4.

7. Etz CD, Homann TM, Rane N, Bodian CA, Di Luozzo G, Plestis KA, et al. Aortic root reconstruction with a bioprosthetic valved conduit: a consecutive series of 275 procedures. J Thorac Cardiovasc Surg. 2007;133:1455-63.

8. Ergin MA, Griepp EB, Lansman SL, Galla JD, Levy M, Griepp RB. Hypothermic circulatory arrest and other methods of cerebral protection during operations on the thoracic aorta. J Card Surg. 1994;9:525-37.

9. Edmunds LH Jr, Clark RE, Cohn LH, Grunkemeier GL, Miller DC, Weisel RD. Guidelines for reporting morbidity and mortality after cardiac valvular operations. Eur J Cardiothorac Surg. 1996;10:812-6.

10. Hagl C, Strauch JT, Spielvogel D, Galla JD, Lansman SL, Squitieri R, et al. Is the Bentall procedure for ascending aorta or aortic valve replacement the best approach for long-term event-free survival? Ann Thorac Surg. 2003;76: 698-703; discussion 703 .

11. Bachet J, Termignon JL, Goudot B, Dreyfus G, Piquois A, Brodaty D, et al. Aortic root replacement with a composite graft. Factors influencing immediate and longterm results. Eur J Cardiothorac Surg. 1996;10:207-13.

12. Koertke H, Zittermann A, Tenderich G, Wagner O, El-Arousy M, Krian A, et al. Low-dose oral anticoagulation in patients with mechanical heart valve prostheses: final report from the early self-management anticoagulation trial II. Eur Heart J. 2007;28:2479-84

13. Koertke H, Zittermann A, Wagner O, Koerfer R. Self-management of oral anticoagulation therapy improves long-term survival in patients with mechanical heart valve replacement. Ann Thorac Surg. 2007;83:24-9.

14. Byrne JG, Gudbjartsson T, Karavas AN, Mihaljevic T, Phillips BJ, Aranki SF, et al. Biological vs. mechanical aortic root replacement. Eur J Cardiothorac Surg. 2003;23:305-10.

15. Doenst T, Ivanov J, Borger MA, David TE, Brister SJ. Sex-specific long-term outcomes after combined valve and coronary artery surgery. Ann Thorac Surg. 2006; 81:1632-6.

16. Ibrahim MF, Paparella D, Ivanov J, Buchanan MR, Brister SJ. Gender-related differences in morbidity and mortality during combined valve and coronary surgery. J Thorac Cardiovasc Surg. 2003;126:959-64.

17. Halstead JC, Meier M, Etz C, Spielvogel D, Bodian C, Wurm M, et al. The fate of the distal aorta after repair of acute type A aortic dissection. J Thorac Cardiovasc Surg. 2007;133:127-35. 